\title{
The Toad Houses as a Symbol of Transformation of Maternity
}

\author{
Young Joo Lee*
}

\begin{abstract}
$<$ Abstract $>$
In this study I analyzed the symbolic meaning of the toad houses made by clients in sandplay therapy. For this purpose, I explored toad houses created by four clients who are experiencing emotional and behavioral difficulties. They sang a lyrics of the song "toad, toad, I will give you an old house, give me a new house" while playing with sand. In order to analyze the symbolism of toadhouses, I examined counseling records that contained verbal and nonverbal expression of the children during the therapy session, sandplay images created by clients, and record of counseling with the mothers. As a result, Four clients were commonly not nurtured warmly in their early lives from their mothers. They were making toad houses at the 'turning point' in relation to the positive mother-child unity phase, when they were getting out of the negative mother-child relationships and attempting psychological independence. In conclusion the toad houses were represented as a symbol of transformation of death and rebirth of maternity in sandplay therapy.
\end{abstract}

Keywords : toadhouse, transformation, maternity

* Psychological Counseling Center for Happy Mind, Counselor (yklisa@hanmail.net) 
Journal of Symbols \& Sandplay Therapy, Vol.10 No.2.

\section{I . Introduction}

The baby begins psychological growth through the relationship with her mother from the moment she is born. Human beings can achieve a strong internal identity and form a healthy ego when their mother's love and their value are authentically expressed to them from the time of their infancy. However, unfortunately, not all babies experience the 'nurturing mother' who envelops her baby warmly, supplies adequate nutrition and free-flowing nurturing, and protects her baby.

Until they reach their childhood after going through their babyhood, children respond to their parents in different ways because they are not capable of distinguishing their parents' influence or will from their inherent instinct (Daton, 2007). Babies who experience through their bodily sense "a terrible or devouring" mother on an archetypal level may grow up with depression or a sense of anger (Lee, 2019). Also, because they fear their dreadful mother, they might excessively adapt to rules or grow up in unhealthy conditions that do not provide an environment that enables their unique development (Jang, 2017).

However, when they finally have begun to meet themselves through sandplay, those clients can experience healing by reflecting on themselves and being immersed in creative play (Kalff, 1980/2009).

The transcendental function of the play acts to transform previously unconscious elements by connecting it to consciousness to give power and courage so that the client can speak about their anger and depression related to the negative mother-child relationship. Children often express their hurt feelings through play because they often cannot express it well when they experience relationship trauma (Lee, 2016).

I began to frequently meet clients who made toad houses in the treatment room. I was curious about whether the construction of toad houses was something that was frequently occurring in the process of sandplay therapy and thus I asked the relevant question to several colleague therapists that I knew. I was surprised because most of them responded that they were unfamiliar with such situations. I was curious why my clients were making toad houses while they were undergoing the process of healing with me, given that toad house making was 
frequently observed from only my clients and was rarely experienced by other therapists. Therefore, I began to review things in common among my clients before and after the time they made toad houses. The results were surprising. All of them were commonly not nurtured warmly at the beginning of nurturing in their early lives with their mothers and were making toad houses at the 'turning point' in relation to the mother-child unity phase, when they were getting out of the cold and indifferent mother-child relationships and attempting psychological independence.

Children are affected by both the positive and negative aspects of the maternal circle as well as the mother of reality (Jang, 2017). When a child experiences cold and negative nurturing, the negative maternal complex is arranged, which causes emotional, physical and social troubles (Rhi, 1987). Park (2017) explained that when a child with attachment trauma experiences sand play therapy, negative maternity is expressed at the beginning of treatment, but gradually changes to motherhood later in treatment. She also said that in the process of changing motherhood, there is a transformation of death, regeneration and integration.

In this paper, I will discuss about the toad hose as a symbol of transformation of death and rebirth of maternity in sandplay therapy.

\section{П. Archetypal and psychological symbolism of toad houses}

Toad houses are made of things that symbolize the Mother such as the earth and water. Making toad houses can be said to be the process of making conscious changes in the client's unconscious regarding the mother-child relationship. The toad house in the state where the left hand has been put into the sand is like the shape of a grave. It is as though the left hand has been swallowed by a grave or entombed. The grave can be symbolic of the archetypal mother (Jung, 1969/2004). The state of being swallowed means a return to the womb and also symbolizes the death of libido. Toads have a poison which they use as an extreme defense. A switch from the memory of the negative mother-child relationship that criticizes and curses to a longing for a warm mother-child relationship in which the child feels 
Journal of Symbols \& Sandplay Therapy, Vol.10 No.2.

nurtured and cared for is made at an unconscious level. The unconscious longing that makes the client go back to the mother's warm breast to find his/her mother again sometimes leaves the mother behind. Obstacles that block the path walked by the hero and threaten his or her ascendance can paralyze courage, just as poison paralyzes. This process resembles a confrontation with the shadow of the mother (Jung, 1969/2004). However, if a human being drinks poisonous liquid, spiritual diseases may occur that may be fatal. Sometimes a death is necessary. To be reborn, the client must die. That is, to give birth to a new relationship with the mother, the old relationship with the mother must die. Therefore, destroying the old house and making a new house can be said to be destroying the relationship with the cold, dreadful mother and forming a new relationship with a warm mother who is often met on an archetypal level in sandplay. When we speak about unity with the Mother, we are of course referring to the dominance of the unconscious in the child's personality. As the ego consciousness of the child develops, we refer to the fact that the child becomes more independent psychologically from the Mother (Neumann, 1974/2009).

Jung(1969/2004) writes about people who may be having relational difficulties in external reality sometimes needing to go inward in his or her orientation to bring some healing that will later have effects in the outer world. In sandplay, we often find that people who have problems with relationships in the outer world need to go through a regression to an earlier stage of development where they can bring healing to that first stage of life, the mother-child unity phase (Weinrib, 1983). Based on my experience as a sandplay therapist witnessing many people making toad houses, I feel that this activity is symbolic of that type of regression that enables healing through a connection with a positive archetypal Mother image. Burrowing into the earth while making a toad house is like being immersed in oneself at a deep psychological level. That is, it is unconsciously going back to the mother that is the earth to tear down the old relationship between ego and unconsciousness and form a new relationship. Escape from the life-threatening, devouring Mother to give birth to a new world, the libido that is tied to the mother in an old, unsatisfactory way must be sacrificed. When making a toad house, the left hand is put deeply into sand and sand is heaped and beaten by the right hand. That is, when the left hand that represents the unconscious is put into the 
world of the unconscious underground, the right hand that represents consciousness continues the motions of dance, of stamping and beating the earth in the world of consciousness which is the earth. This act of beating sometimes looks like the repetition of childlike "foot stamping'. The act of foot stamping in babyhood is related both to the pleasure felt in the relationship with the mother, as well as an act of independence against the mother. It is also an act that has been already manifested to quickening in the womb. This act of foot stamping also means an attempt to go back to the womb. In explanation, the repetition of the act of beating with the hand is like beating a drum in a rhythm reflected in dances. Such dance rhythms may move those who dance into a state of unconsciousness (that is, a womb-like state) or a state of heightened or unusual consciousness, such as that experienced by the Sufis through their whirling dances.

Toad houses can never be made on dry land. An appropriate amount of water is indispensable to make toad houses well. Water is a symbol of the unconscious and enables rebirth. Mythology provides stories of the lives of heroes who often are abandoned for some reason by their original mothers and who are adopted or cared for by a second mother who can nurture them. We understand these mother-child dynamics in terms of the original mother being a human mother that actually exists, while the second mother is a symbolic conceptual mother that is divine, supernatural and archetypal (Jung, 1967/2004). When I hear clients sing the song, "Toad, toad, I will give you an old house, give me a new house." It feels that the words reflect this two-mother concept and paves the way for healing in relationship to the Mother.

\section{The symbolism of toads differs by country and culture.}

\section{1) Toads are symbolism of Ambivalent of 'good' and 'evil'}

Toads are regarded as evil in some culture areas and as good in other cultures. The Celts believed that swamps or waterfalls were paths to the underworld and boundaries between this world and the other world. Therefore, they regarded toads that can live both in swamps and on the land as the grim reapers (the angels of death) who come and go between this world and the other world. In Slavic countries, the mushroom called Zabaci Huby is called the 
Journal of Symbols \& Sandplay Therapy, Vol.10 No.2.

toad-mushroom because the hallucinating fungus pilz in the mushroom is similar to the psychotropic toxin in the skin of toads. The Gypsies or Romany fear toads because they believe that a toad jumping up to the top of their foot signals death. People who live in the vicinity of the Pyrenees mountains believed that a method of distinguishing witches from normal people was to identify a toad's foot stamp on the left eye of each witch (Cooper, 1978/1994). On the contrary, toads are viewed as positive symbols in China, Japan, and Korea. In China, toads are known as animals that guide Taoist hermits with miraculous powers (Mittford \& Wilkinson, 2008/2010). Relationships with toads are sometimes expressed through extraordinary beings, such as the immortal shown playing with the toad in Fig. 1.

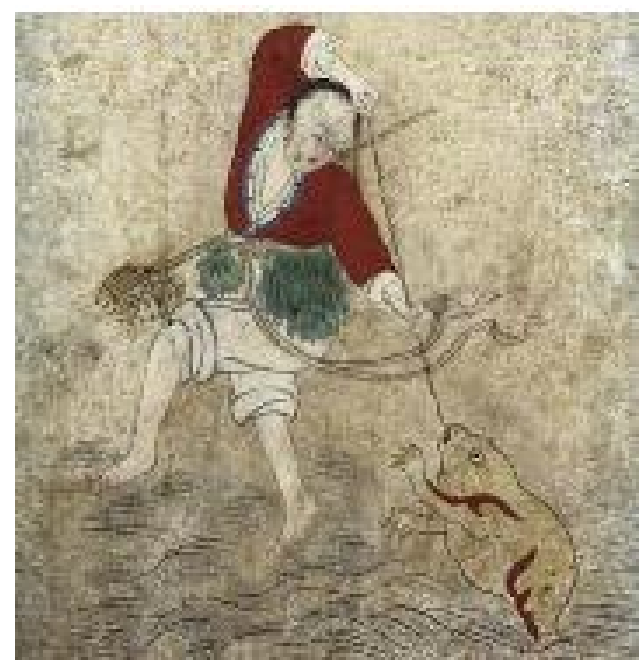

Fig. 1. Painting of Yu-Hae (an immortal) who plays with a toad

Toads are animals that are loved as toads of good fortune symbolizing monetary profits, money, and good fortune because they hold round objects like coins in their mouth. It is said that in Japan, toad figures made of jade were put into the deceased to pray for the repose of the deceased (Lee \& Hwang, 2013). In Korean folk tales, toads are described as animals that return a favor. One day, a toad visited the house of a maiden. Feeling sorry for the toad, the maiden gave leftover food to the toad. The maiden reared the toad for one year as such. When one year and some more days had passed, the maiden was offered to a 
centipede as a sacrifice by the village and the toad reared by the maiden appeared to fight a bloody fight. Eventually, both the toad and the centipede died in the fierce fight and the maiden escaped death thanks to the death of the toad (Kim, 2001). Another figure of a man riding on a toad is sometimes used in Sandplay as a representation of the archetypal Father (Fig. 9) who unites Spirit and Nature (Weinberg, 2013).

\section{2) toads have symbolism of transformation}

Toads' lives begin in water. They have a dramatic growth and development period in which they hatch from their eggs, undergo the process of tadpoles, and finally become adult toads to become capable of living outside water. They are the animals on the earth that can undergo the largest physical and mental changes while moving from the ocean to the land (Baek, 2007). Water symbolizes the unconscious and is a material principle of all objects. In addition, as shown by the 'rebirth' experienced by Christ in the Jordan River, water is a place of maternal depths and rebirth (Jung, 1969/2004). Toads, in their early phase, are born into the water and as they mature past the tadpole stage and develop legs, they climb out onto the land. Symbolically, we associate the land, earth, with everyday life and consciousness. However, going deeper philosophically and reflecting Jung's words (Jung, 1969/2004), we also can consider that in the earth lives the soul of the earth (Seele) and the spirit of life (Geist). All creations obtain energy from the soul of the earth. Like mothers who give birth to their children and nurture that life they have given, the earth too nurtures its creations.

\section{3) Toads symbolize a raw material in alchemy}

In Figure 2, a toad can be seen at the root of a tree in an illustration where the tree is described as a tree of alchemy (Jung, 1967/2004). A major core of alchemy is transformation. In this context, the transformation of toads from aquatic animals to land animals symbolizes transformation in alchemy. 
Journal of Symbols \& Sandplay Therapy, Vol.10 No.2.

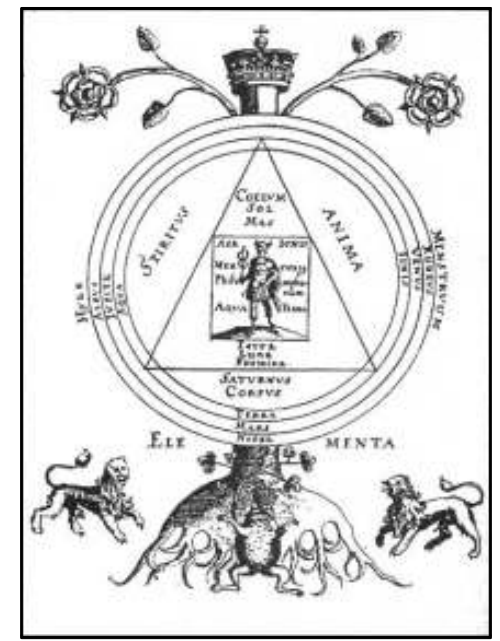

Fig. 2. Toads symbolize a raw material in alchemy (Jung, 1985)

In Figure 3, we see a toad at the centre of Ripley's alchemical drawing. In alchemical illustrations, such as this one, toads are sometimes shown along with snakes. Victims suffering from snake bites were sometimes treated with toad poison which was said to be stronger than snake venom. Thus, toad venom was considered as a healing agent. Snakes, even when venomous, are also often associated with healing. When the poison of the toad and the healing though poisonous power of the snake are combined (as through the alchemical process), the healing energy is more powerful than when it is not combined.

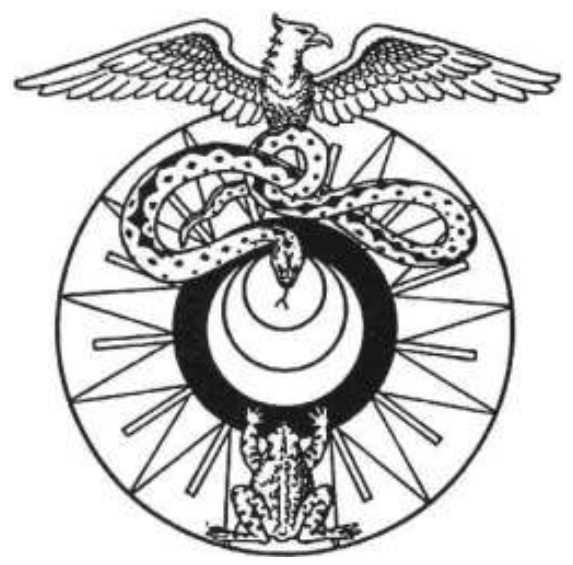

Fig. 3. Alchemical drawing of George Ripley 


\section{4) Toads are a symbol of fertility and femininity}

Fertility or creativity is part of the basic nature of the Feminine (Neumann, 1974/2009). Toads are a symbol of fertility in many cultural areas in the world. This is related to the fact that toads spawn many eggs at a time and the fact that toads are related to water and rain that enable crops to grow. In Egypt, crops are raised in the surroundings of the Nile River that become fertile after flooding. As the amount of flood waters of the Nile River decreases, numerous frogs are left in swamps that have been filled with water. Because frogs have been related to water as such, frogs have come to be regarded as a symbol of a very prolific fertility in Egypt. As the water level of the Nile River becomes lower, Heket who is a daughter of Ra, the sun-god of Egypt takes charge of revival as the goddess of childbirth and a guardian of the deceased (Fig. 4). Heket is a goddess with a head that looks like that of a frog which symbolizes life and richness and it is said that Egyptian women carried an accessory made in the shape of Heket on themselves (Ions, 1968/2004).

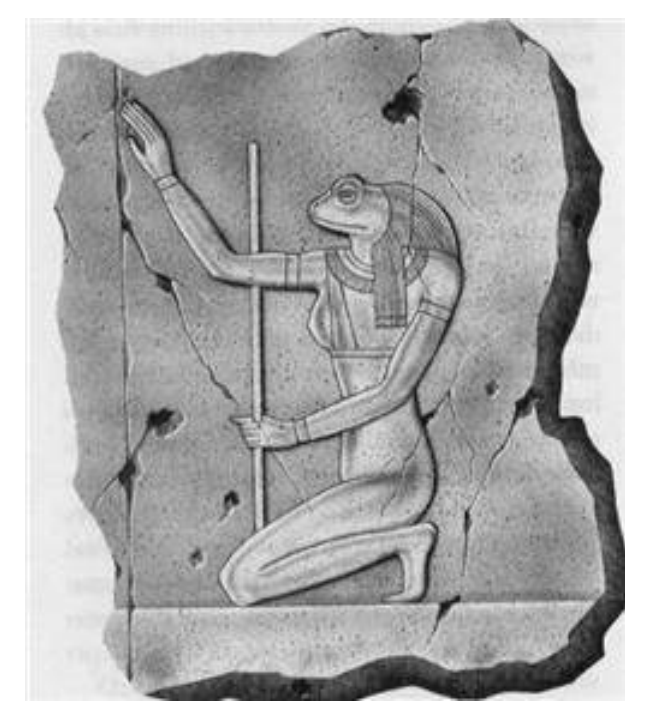

Fig. 4. Heket, the Egyptian goddess of childbirth and guardian of the deceased

In pre-Colombian Measoamerica, many tribes worshipped a goddess known as Ceneotl, the patron of childbirth and fertility, who took the form of a frog or a toad with many udders. Also, frogs and toads were considered spirits of rain, and were used in many rituals 
Journal of Symbols \& Sandplay Therapy, Vol.10 No.2.

intended to bring the rains. The Aymara tribe of Peru and Bolivia made small frog images, which they placed on hilltops, to call down the rain. Indeed, if the rains failed, some tribes blamed the toads for withholding the rain, and would lash them in punishment. The early Aztecs saw the toad as Tlaltecuhti, the earth mother goddess, who embodied the endless cycle of death and rebirth. She appears either as a real toad or in quasi-human form. With clawed feet and a gaping fanged mouth and her joints are adorned with human skulls. She usually appears in a squatting position, giving birth to the new world, while dying souls pass through her fanged mouth to the netherworld. In one legend, she is the source of the entire universe: Quetzalcoatl, the bird-serpent god, and Tezcatlipoca, the magician-jaguar god, find her floating alone on the primordial sea. They tear her body in half, with one half forming heaven, and the other forming the earth. Some common Mesoamerican toads are known to cannibalize their own and other toad species, which may explain the use of the toad as the image of destruction as well as fertility or rebirth. (www.exploratorium.edu)

In Korean folk tales, toads are regarded as the spirit of the moon. A story about Hang-a, who was a goddess has been handed down in which Hang-a was exiled to the world of human beings together with her husband who was a god. She went up to the sky after eating all the elixirs of life including that of her husband so she could stay in the moon. While waiting for her husband in the moon, Hang-a gradually became tired and her body shrunk to become a toad with a bumpy back due to her regret for her husband and sorrow (Kim, 2001).

5) The toad house, as an example of house, cave, as a symbol of great mother energy

Along with temples and graves, the house is a symbol of Great Mother energy (Neumann, 1974/2009). When constructed, toad houses are similar to caves in shape. A cave is sometimes called the womb of the earth where all beings appear and it is the center of the beginning of life and a sacred place. Going into a cave in sandplay symbolically is giving birth to a new possibility from the deep inner world. Therefore, mental rebirth occurs in a cave sometimes (Turner, 2005/2009). In addition, caves have ambivalence. They were major 
residential spaces in primitive times, shelters for protection against dangers as well as places where children were cared for and nurtured. However, they were also the secret and dark world of the deceased that would sometimes cause fear and anxiety (Jung, 1969/2004).

\section{Toad houses in clients' sandplay processes.}

The sandpictures of four clients who are created toad houses are presented. This study examined how the toad houses symbolically appear when children who experienced negative motherhood changes into the positive maternal prototype through the course of sandplay therapy, which was implemented for the purpose of addressing the behavioral and emotional difficulties of the children.

\section{Case 1) Toad house created by a nine-year-old girl}

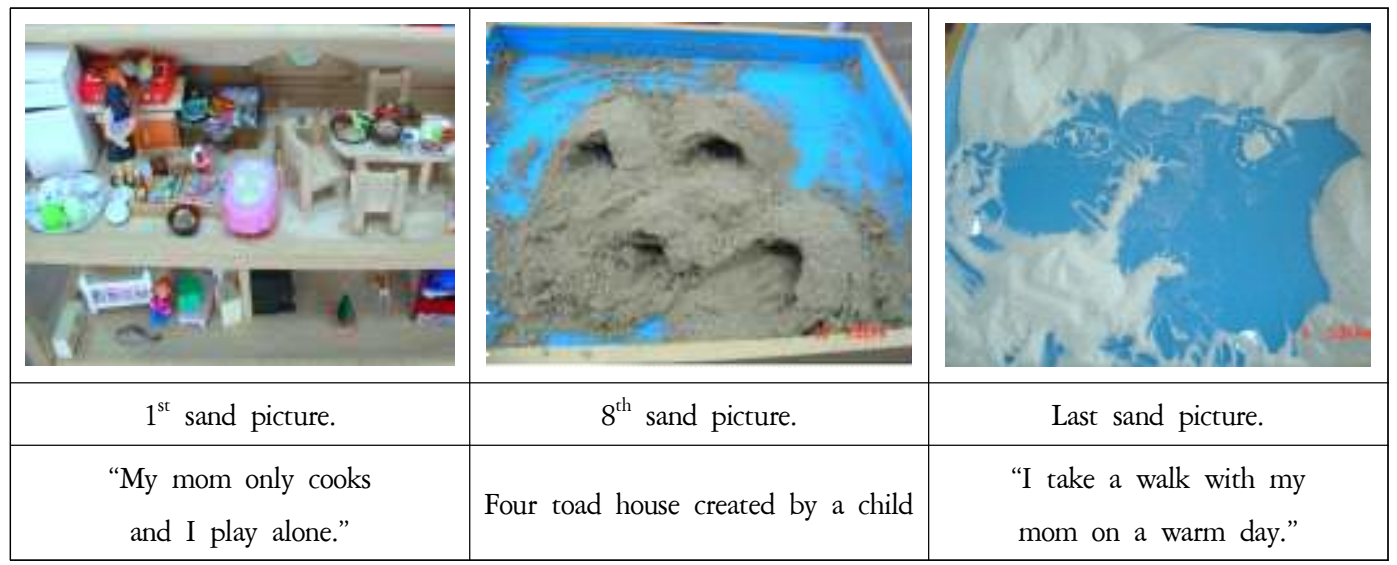

Fig. 5. Toad house created by a nine-year-old girl

The mother of the child gave birth to the child although the pregnancy of the child was not wanted to the extent that the child's father recommended that the pregnant woman abort the child because the child was conceived before marriage. The mother of the child nurtured the child in depressed conditions to the extent that she wanted to die herself although she did not attempt suicide. When she was approximately five years old, the child 
Journal of Symbols \& Sandplay Therapy, Vol.10 No.2.

was once diagnosed by a psychological therapy institution as having conditions similar to autism. Thereafter, the child was taken to the center when she was approximately nine years old because her eye contact was unnatural and she could not establish good peer relationships.

After 8 therapy sessions in which the child seemed to be making progress and experiencing some healing from her early wounding, she made four toad houses successively in the sandtray. Toads are animals that have poison. Given that the act of digging the relic originated in her unconscious, there may be things that may be poisonous in her unconscious. The four toad houses are significant in that they encourage the child to gain the great mother's energy. The number four is the symbol of femininity. So she needed four toad houses to develop her femininity (Turnner, 2005/2009).

Babies are delighted to have a symbiotic experience with their mother when they are warmly hugged, protected, and sympathetic. However, children who experience neglect from their depressed mothers are hampered by self-development, which results in lowered self-worth and fragmented self (Jang, 2017). The mother of the child began to treat depression, gained a better understanding of the child and tried to spend time together.

Case 2) Toad house made by a seven-year old girl

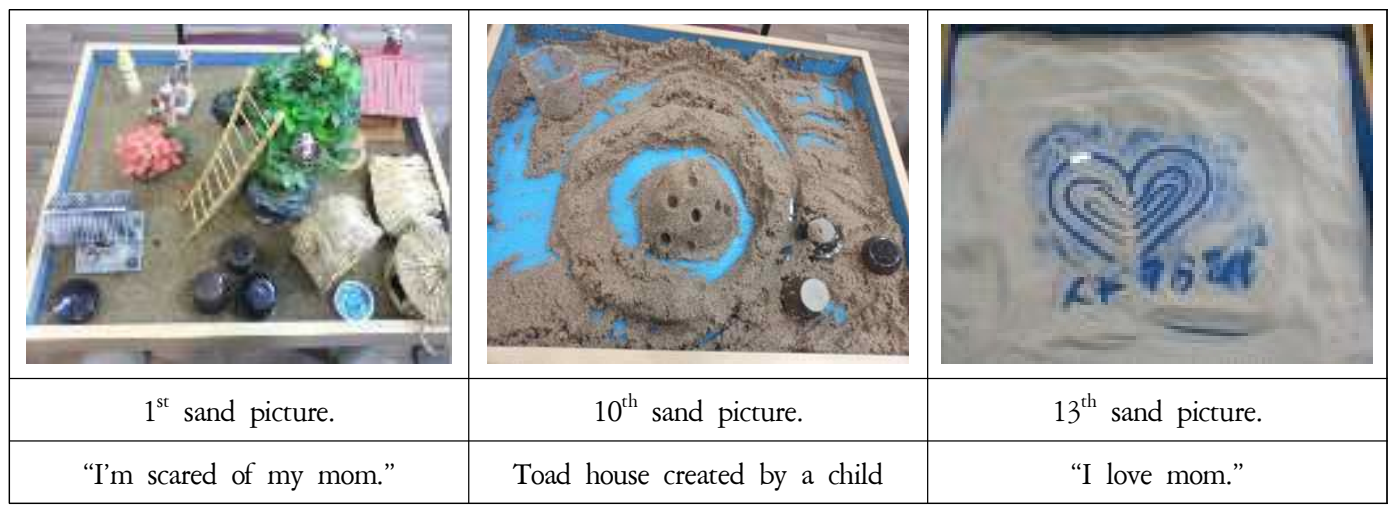

Fig. 6. Toad house created by a seven-year-old girl

This child was brought by her mother to therapy because she was overly shy and intimidated in external activities such as those in kindergarten while being quite irritated and 
excessively aggressive towards her mother. It was reported by her mother that the child's mother regards social achievement important and that she made the child study too much from when the child was approximately two years old. She also sometimes punished the child by driving the child out of the house when the child did not complete an assignment or when she grimaced when directed to do an assignment. The child who was obedient until she was approximately six years old suddenly began to curse her mother bitterly or act out aggressively. She made holes in the toad house with her finger after making the toad house (Fig. 6). This is the toad house of a child very angry at her mother who had been very overpowering of the child for many years. As we see, there is not entrance to this toad house. There are only intrusive holes caused by intrusions from the outside. After the session of the toad's house, the child had a play involving improper rearing, such as a baby cradle alone in the room and hungry. The mother, who could understand the anger of the child, did not force the child to study and tried to play with her. The child expressed her mother's bad parenting experience and negative maternal complex as a toad house. The child was able to express his feelings honestly, and apologized from her mother about inappropriate and scary nurturing. And she could increase positive emotional exchanges with her mother.

The old mother who was angry and screaming was the old house of the toad. Instead of, the mother of a new house was born to understand and play with the children.

Case 3) Toad house of an eight-year old boy

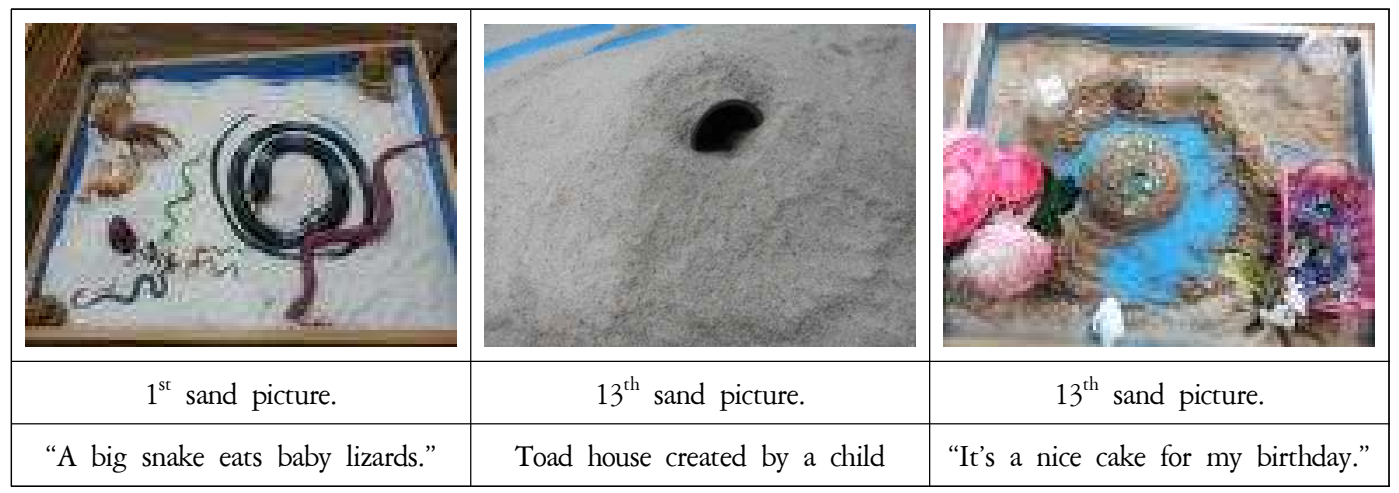

Fig. 7. Toad house constructed with a jar by an eight-year-old boy 
Journal of Symbols \& Sandplay Therapy, Vol.10 No.2.

This is a toad house created by an eight-year old boy who was brought to therapy because he was quite aggressive and violent in his language and behavior. The boy's mother and father frequently fought. When they did so, his mother often told the child that she would leave the house, something which made the child very anxious. When his mother pretended to go out of the house after fighting with her husband many times, the child would frantically go out to find his mother, even sometimes wearing no shoes. When the child had a trifling quarrel or made a mistake, his mother would threaten the child by telling him that the police would arrest him. His mother actually took him to the entrance of a police station sometimes, a fact that the child remembered from his past in detail and told it to the therapist. From the middle phase of the treatment, the child's violence and aggressiveness began to disappear almost completely after his mother apologized to the child about her running away from home and threatening him with regard to the police.

Psyche and reconstruction of the ego, were contained in the jar ("hangari" in Korean). This is a container for maturing foods. During this transformative process, the container is closed and it is put in the dark. Later the jar is opened to the sunlight. The maturing process reminds one of the alchemical process that occurs in therapy when unconscious contents and processes may later come to consciousness. We could say that, through the transformative process. It seems that the insecure attachment of this boy to his parents is represented in the unreliable dry sand which will not stay where he puts it. Perhaps the jar represents the therapeutic containment of sandplay and the therapist, providing him with the structure that allows him to consider the transformative possibility of toad house.

Sand play therapy, along with a therapist, a good mother archetype, is capable of reconstructing the mother-child primitive relationship and providing an environment for reproducing the damaged ego-Self axis (Jang, 2017). 
Case 4) Toad house of a seven-year old boy

\begin{tabular}{|c|c|c|}
\hline & & \\
\hline $3^{\text {th }}$ sand picture. & & \\
\hline "All have to be spaced & An idler lying on a sofa is placed & "The animals are free. \\
regular apart." & at the entrance of a toad house. & I'm free too." \\
\hline
\end{tabular}

Fig. 8. Toad house created by a seven-year-old boy

This child has grown up reared by his mother who, according to her report, had obsession and mysophobia (a pathological fear of contamination and germs). From when he was approximately three years old, he had been obediently performing the large amount of studies presented by his mother and had been evaluated by others as "exemplary" and "gentlemanly" but he bit his nails and obsessively organized things. Although the child had been always obedient to his mother, as the treatment progressed, he sometimes disobeyed and refused the assignment given by his mother telling her that the amount was too large. As he expressed his emotions to his mother, his organizing and obsessive habits were no longer apparent and he seemed to be able to live a much more natural and easy daily life. This young boy made his toad house when he had developed the capacity to express his emotions and had become self-assertive. He is free from his mother's order or regulation. This toad house was made from wet sand which is strong in its structure and is helping him to transform his feelings of frustration and anger into a self-regulated life. The child demolished the world that moves according to the instructions, directions or rules and seems to have come to live an instinctive life suitable for a seven-year-old boy. For this boy, a new toad house means living away from a forced schedule and living on a child's instinct. 
Journal of Symbols \& Sandplay Therapy, Vol.10 No.2.

\section{Conclusion}

Human beings can achieve a strong internal identity and form a healthy ego when their mother's love and their value are authentically expressed to them from the time of their infancy (Kalff, 1980/2009). However, unfortunately, not all babies experience the 'nurturing mother' who envelops her baby warmly, supplies adequate nutrition and free-flowing nurturing, and protects her baby. Until they reach their childhood after going through their babyhood, children respond to their parents in different ways because they are not capable of distinguishing their parents' influence or will from their inherent instinct. Babies who experience through their bodily sense "a terrible or devouring" mother on an archetypal level may grow up with depression or a sense of anger. Also, because they fear their dreadful mother, they might excessively adapt to rules or grow up in unhealthy conditions that do not provide an environment that enables their unique development. However, when they finally have begun to meet themselves through sandplay, those clients can experience healing by reflecting on themselves and being immersed in creative play (Kalff, 1980). The transcendental function of the play acts to transform previously unconscious elements by connecting it to consciousness to give power and courage so that the client can speak about his/her anger and depression related to the negative mother-child relationship.

The instinctive energies, such as emotions of clients to go back to a childlike state lacking the discriminatory ability when they experience regression in sandplay can be also their parents' attributes. The instinctive energies represented by 'toads' given by children to the symbol of mother represented by 'house' is meaningful.

As we have seen in the scientific section on toads, these creatures have a characteristic of transformation as they progress from their egg state and birth in water, emerging from the water when they have matured to live most of their lives on land. They also have a poison in their body which, although toxic, is connected to healing. As unconscious elements become consciousness through the therapeutic work, clients may both sense the toxicity of their mother(or father) and still make changes in their lived life lived by learning to regulate their emotions and resist against complete adaptation and obedience to the parent, especially when it 
is harmful to them. This transformative process often requires a "death" for which we can use the metaphor of the fatality of the toad poison. Such a death may enable a spiritual transformation and rebirth. Such a death requires a descent into the unconscious, often in the form of a regression which takes them back to an early stage of life where reparation of wounding can occur. My premise in this paper is that the toad houses are representative of the descent to the unconscious, that is, "into the earth," and regression "into the positive archetypal Mother" that could be symbolized by a cave or a grave. In this way, they sacrifice their libido that has been tied to their personal mother. Each of the examples given above represents a different aspect of connecting to a new maternal energy through the transformative symbol of the toad house.

The clients were abandoning their perceptions of a cold, often intrusive and threatening mother in favor of a divine, sometimes numinous experience of the positive archetypal Mother. In the process, they were being reborn as true heroes in their psyches.

\section{References}

Baek, S-N. (2007). The toad. Paju: Bori Publishing Co.

Cooper, J. C. (1978). An illustrated encyclopedia of traditional symbol. Thames and Hudson Ltd. (Trans. into korean in 1994).

Dayton, T. (2007). Emotional sobriety. Florida: Health communication, Inc.

Ions, V. (1968). Egytian mythology. Seoul: Beomwoo Publishing Co. (Trans. into korean in 2004).

Jang, M-K. (2017). Analytical psychological sandplay therapy. Seoul: Hakjisa.

Jung. C. G. (1967). Collected Works 6. Princeton, NJ: Princeton University Press/ Bollingen.

(Trans. into korean in 2004).

Jung. C. G. (1969). Collected Works 8. Princeton, NJ: Princeton University Press/ Bollingen.

(Trans. into korean in 2004).

Kalff, D. M. (1980). Sandplay: A psychotherapeutic approach to the psyche. Cloverdale, CA: 
Journal of Symbols \& Sandplay Therapy, Vol.10 No.2.

Temenos Press. (Trans. into korean in 2009).

Kim, J-D. (2001). A symbol system of our culture. Seoul: Darensesang Publishing.

Rhi, B-Y. (1987). Jung's maternal image and mother complex theory. Shim-song yon-gu. Vol 2, 73-88.

Lee, Y-A. (2016). An analysis of posttraumatic play characteristics of an abused child in play therapy. Korean journal of play therapy, 194), 335-362.

Lee, Y-J. (2019). A study about the maternal symbols in the sandplay therapy process of the child who experienced relationship trauma. Korean journal of child psychotherapy, 14(2), 77-96.

Lee, U-D. \& Hwang, R-G. (2013). Medicinal fauna china. Beijing: Bokgengwagi(福建科技) Publishing.

Mittford, M. B. \& Wilkinson, P. (2008). Signs and Symbols. Paju: Book 21 Publishing Co. (Trans. into korean in 2010).

Neumann, E. (1974). The great mother. Seoul: Sallim Publishing. (Trans. into korean in 2009).

Park, J-H. (2017). A study on the mother symbols in folktales and mythologies. Studies in humanities. Vol 52, 137-163.

Turner, B. A. (2005). The handbook of sandplay therapy. Temenos press. (Trans. into korean in 2009).

Weinberg, B. (2013). The presence of the Father in Sandplay. Paper presented at the KSST 3rd Annual Conference, Seoul, Korea.

Weinrib, E. (1983). Images of the self: The sandplay therapy process. Boston, MA: Sigo Press. http://www.exploratorium.edu/frogs/folklore/folklore_4.html 